\title{
Elaborate Mimetic Vocal Displays by Female Superb Lyrebirds
}

\author{
Anastasia H. Dalziell ${ }^{1,2,3 *}$ and Justin A. Welbergen ${ }^{3}$ \\ ${ }^{1}$ Cornell Lab of Ornithology, Cornell University, Ithaca, NY, USA, ${ }^{2}$ Department of Neurobiology and Behavior, Cornell \\ University, Ithaca, NY, USA, ${ }^{3}$ The Hawkesbury Institute for the Environment, Western Sydney University, Richmond, NSW, \\ Australia
}

OPEN ACCESS

Edited by:

Michelle L. Hall,

University of Melbourne, Australia

Reviewed by:

Ximena J. Nelson,

University of Canterbury, New Zealand Kristal E. Cain

Australian National University, Australia

${ }^{*}$ Correspondence:

Anastasia H. Dalziell

anastasia.dalziel/@cornell.edu

Specialty section:

This article was submitted to Behavioral and Evolutionary Ecology, a section of the journal

Frontiers in Ecology and Evolution

Received: 10 December 2015

Accepted: 22 March 2016

Published: 20 April 2016

Citation:

Dalziell AH and Welbergen JA (2016)

Elaborate Mimetic Vocal Displays by

Female Superb Lyrebirds.

Front. Ecol. Evol. 4:34

doi: 10.3389/fevo.2016.00034
Some of the most striking vocalizations in birds are made by males that incorporate vocal mimicry in their sexual displays. Mimetic vocalization in females is largely undescribed, but it is unclear whether this is because of a lack of selection for vocal mimicry in females, or whether the phenomenon has simply been overlooked. These issues are thrown into sharp relief in the superb lyrebird, Menura novaehollandiae, a basal oscine passerine with a lek-like mating system and female uniparental care. The spectacular mimetic song display produced by courting male lyrebirds is a textbook example of a sexually selected trait, but the vocalizations of female lyrebirds are largely unknown. Here, we provide the first analysis of the structure and context of the vocalizations of female lyrebirds. Female lyrebirds were completely silent during courtship; however, females regularly produced sophisticated vocal displays incorporating both lyrebird-specific vocalizations and imitations of sounds within their environment. The structure of female vocalizations varied significantly with context. While foraging, females mostly produced a complex lyrebird-specific song, whereas they gave lyrebird-specific alarm calls most often during nest defense. Within their vocal displays females also included a variety of mimetic vocalizations, including imitations of the calls of dangerous predators, and of alarm calls and song of harmless heterospecifics. Females gave more mimetic vocalizations during nest defense than while foraging, and the types of sounds they imitated varied between these contexts, suggesting that mimetic vocalizations have more than one function. These results are inconsistent with previous portrayals of vocalizations by female lyrebirds as rare, functionless by-products of sexual selection on males. Instead, our results support the hypotheses that complex female vocalizations play a role in nest defense and mediate female-female competition for breeding territories. In sum, this study reveals elaborate female vocal displays in a species widely depicted as an example of sexual selection for male extravagance, and thus highlights the hidden complexity of female vocalizations.

Keywords: female song, female ornaments, lyrebird, Menura novaehollandiae, nest defense, sexual selection, vocal mimicry

\section{INTRODUCTION}

Songbirds have so been named for their elaborate and aesthetically pleasing vocalizations, and until recently (Odom et al., 2014) their 'songs' were assumed to be primarily the result of selection on males for attracting mates or repelling rivals (Catchpole and Slater, 2008). However, evidence has been accumulating that not only do female oscine passerines regularly sing, but also that their 
vocalizations play an important role in mediating female fitness. Compellingly, a recent analysis showed that female song is an ancestral trait in the oscine passerines (Odom et al., 2014), adding weight to earlier suggestions that the contemporary research focus on species that have little or no song in females has led to a distorted perspective on the sex-specificity of elaborate vocalizations in birds (Langmore, 1998; Hall, 2004; Riebel et al., 2005). Thus, there is now a strong impetus to understand the role of vocalizations in female oscine passerines to address this research imbalance.

While interest in female vocalizations is growing, it is currently restricted to studies of species-specific song and calls (Dalziell et al., 2015). However, between 20 and 40\% of songbirds regularly imitate the sounds in their environment, such as those made by other species including birds and mammals, as well as mechanical sounds (Dalziell et al., 2015). Some of the most complex songs produced by male oscines around the globe incorporate imitations of heterospecifics. Such 'vocal mimics' include European starlings Sturnus vulgaris (Eens, 1997), marsh warblers Acrocephalus palustris (Dowsett-Lemaire, 1979), northern mockingbirds Mimus polyglottos (Gammon and Altizer, 2011), Lawrence's thrush Turdus lawrencii (2010), and chorister robins Cossypha dichroa (Harcus, 1977). However, research into the mimetic vocalizations of females is conspicuously absent. Here we provide the first investigation into the mimetic and non-mimetic vocalizations given by females of one of the world's best-known and most versatile vocal mimics, the superb lyrebird, Menura novaehollandiae.

Superb lyrebirds are a large $(\sim 1 \mathrm{~kg})$, basal oscine passerine, with a slow life-history and with all the hallmarks of a species where males are under strong sexual selection. Adult males (>6 years) possess a spectacular tail (Smith, 1999, 2004) that they exhibit during sophisticated coordinated song and dance performances to females (Dalziell et al., 2013). Song and dance displays are performed on display arenas known as 'mounds' a circular patch of cleared ground on the forest floor (Higgins et al., 2001). During the breeding season, a single male will construct and maintain several mounds on a territory, which he defends from other males in a lek-like mating system (Higgins et al., 2001; Dalziell, 2012). Females are more cryptic in appearance, lacking the ornate tail feathers possessed by males. A single female builds a nest and cares for a single young (Lill, 1979a), and during this time defends a foraging/breeding territory from other females (Higgins et al., 2001). Females, like males, are seasonally territorial, and will defend the same territory in successive breeding seasons (Higgins et al., 2001).

Male lyrebirds are highly accomplished vocal mimics and also produce a diverse array of lyrebird-specific songs; however, the vocalizations of female lyrebirds are almost completely unknown. Male advertisement song is loud and complex, with $70-80 \%$ comprising highly accurate imitations of the vocalizations of sympatric species of birds (Robinson and Frith, 1981; Smith, 1988; Robinson and Curtis, 1996; Zann and Dunstan, 2008; Dalziell and Magrath, 2012). Males sing extensively during midwinter when most eggs are laid (reviewed in Higgins et al., 2001), and vocal displays immediately precede copulationscharacteristics consistent with a sexually selected trait. In contrast, female vocalizations are only given cursory mention-if at all-and are usually described as rare (Higgins et al., 2001) or performed less "skillfully" than by males (Lill, 2004). There are no descriptions of lyrebird-specific 'song' sung by females, but while some authors specify that females do not produce lyrebird-specific song (Lill, 2004) there are also descriptions of female lyrebirds that 'sang' as they defend their nests (e.g., Reilly, 1970, p. 69). There are, however, several anecdotal reports of breeding female lyrebirds imitating other species of bird (e.g., Cook, 1915; I. W., 1944), particularly when humans approach the nest or newly fledged young (e.g., Kitson, 1905; Robinson, 1975). Robinson (1975) dismisses these mimetic vocalizations as a "displacement activity" (Robinson, 1975, p. 24; sensu Delius, 1967). However, this conclusion seems premature given the absence of any systematic study on female lyrebird vocalizations. Moreover, the propensity for female lyrebirds to vocalize may have been underestimated because adult females ( $>4$ years) have almost identical plumage to immature males ( $3-5$ years) so that vocalizing females can easily be mistaken for vocalizing young males.

In this study we examined the structure and context of the vocalizations of female superb lyrebirds. Our preliminary observations indicated that, like males, breeding female lyrebirds regularly call, sing, and imitate other species. If female vocalizations are functionless by-products of selection for song and complex mimetic vocalizations in males, then their acoustic structure should not vary predictably with ecological context, and should be similar to that of males. Alternatively, if female vocalizations are the result of distinct selective forces acting on females, then they should vary predictably with female-only activities, such as female-female competition for foraging/breeding territories and nest defense. Furthermore, the acoustic structure of female vocal displays should differ from that of males. Here we examine these predictions by the analysis of recordings of wild female lyrebirds made in three different ecological contexts: (i) foraging, (ii) nest defense, and (iii) visits to courting males. We then discuss how female vocalizations differ from those reported in males.

\section{METHODS}

We studied nesting female superb lyrebirds in the Jamison Valley $\left(-33.76^{\circ}, 150.33^{\circ}\right)$ within the Blue Mountains National Park in New South Wales, Australia. The valley is partially enclosed by sandstone cliffs and contains a mosaic of different habitats, but lyrebirds predominantly occupy sections of wet sclerophyll forest, and patches of temperate rainforest found along creek lines and in the shelter of the cliffs.

We recorded female lyrebirds between June and September in 2014 and 2015. The breeding season begins in winter and comprises two distinct parts. From May until mid-July, eggs are laid and adult male lyrebirds display and sing extensively. When fertile, a female lyrebird will leave her own territory and approach a male lyrebird on his territory. The male will then entice the female to one of his display mounds, where he displays (Higgins et al., 2001). A female may visit several males on these display evaluation forays before mating (Lill, 1979a), which takes place on the display mound itself (Higgins et al., 2001). By late-July most adult males have begun their annual tail molt, when they 
replace all their tail feathers at once. At this time male display activity rapidly decreases and males are less territorial. By this second stage of the breeding season, females are incubating and defending territories from other females. Females incubate their clutch (of one egg) for 6-7 weeks (Reilly, 1970; Lill, 1979a,b). The chick remains in the nest for a further 6-7 weeks and is brooded by the female. Once the chick fledges, the female's territory boundaries appear to dissolve but the fledgling will remain with its mother for several months and often until she nests again, which is usually in the following winter (AHD et al., unpublished data). While females and immature males can have identical plumage, during the incubation and nestling breeding stages the long tails of nesting females become bent sideways from sitting inside their dome-shaped nest. Since, in this species males never incubate (Reilly, 1970; Lill, 1979a), a bird with such a bent tail can be reliably identified as a breeding female.

\section{Recordings}

To examine the structure and context of the vocalizations of female superb lyrebirds, we recorded breeding females during three ecological contexts: foraging, nest defense, and courtship.

\section{Foraging and Nest Defense \\ Foraging}

We observed and sound-recorded 10 individual foraging females known to be incubating or brooding (recordings were 18$122 \mathrm{~min}, \bar{x}=54 \mathrm{~min}$ ). For three females for which the nest was known, we followed the individual from the moment she left her nest in the morning for up to $2 \mathrm{~h}$. Other females were recorded in the vicinity of known nests or were recorded opportunistically. All recordings of foraging forays took place between 7 a.m. and $12 \mathrm{p} . \mathrm{m}$. The female lyrebirds that were foraging were clearly habituated to human presence (for example, some continued foraging as members of the public ran past within $5 \mathrm{~m}$ ) and thus it is unlikely they responded to the observer as a threat. We also watched for the presence of predators as these might confound our recordings. Accordingly, we excluded from our analysis the final portion of a recording of one female after detecting the presence of a gray goshawk, Accipiter novaehollandiae (a predator of lyrebirds: Lill, 1980).

\section{Nest defense}

We observed and sound-recorded eight individual females when we approached nests to band and measure nestlings (recordings were 8-42 $\mathrm{min}, \bar{x} 21.6 \mathrm{~min}$ ). When humans come close to an active lyrebird nest, female nest owners defend their nest by closely approaching the intruder and performing visual and vocal threat displays (sometimes leading to physical attack). These responses are consistent with those observed during natural nest disturbances (Supplementary Video S1). Thus, we are confident that our presence at the nest simulated a nest predator (see also Frid and Dill, 2002). Focal females were chosen randomly but we excluded from our analysis one recording of a female because for the majority of the recording she vocally interacted with another lyrebird. This prevented vocalizations from being attributed to specific individuals and rendered the context qualitatively different from the other recordings of a single female defending her nest.

Sound recordings of females foraging and defending their nest were obtained with a hand-held Sennheiser ME 66/K6 shotgun microphone and either a Maranz PMD 661 or a Roland R-26 digital recorder, set to sample at $48 \mathrm{kHz}$ and 24 bits. We were careful to include in our analysis only sounds that originated from the focal lyrebird. In practice this was straightforwardthe vocalizing lyrebird was in view or temporarily out of view in a known location during recordings. While model species were very rarely close by, we noted any other species viewed during the recording to identify cases where it was not possible to reliably assign the vocalizations to the lyrebird or the model. Accordingly, of 250 mimetic vocalizations identified among recordings, we excluded two vocalizations from our analysis because a model species was close by (a white-browed scrubwren, Sericornis frontalis, in both cases).

\section{Courtship}

We examined the role of female vocalizations during sexual interactions using 27 different videos of 15 different males interacting with females on display mounds. To record courtship displays, we placed motion-sensitive camera traps (Bushnell NatureView HD Max) at male display mounds. Once triggered, cameras recorded $60 \mathrm{~s}$ of video (resolution $1920 \times 1080 \mathrm{p} @ 30$ fps) and sound (44.1 kHz, compressed as MP3 @ $64 \mathrm{kbps}$ ) before retriggering.

\section{Acoustic Classification of Female Lyrebird Sounds}

We found that, like males (Zann and Dunstan, 2008; Dalziell, 2012), female lyrebirds could produce a bout of continuous but varied sound. However, these bouts could be broken up into vocalizations. We formally defined a 'vocalization' as a continuous sequence of sound containing elements that were all of one of the following four mutually-exclusive 'types' lyrebirdspecific 'alarm calls', lyrebird-specific 'whistle song', 'mimetic vocalizations', or 'unknown' (details below). Vocalizations were considered finished when the bird was silent for two or more consecutive seconds (thus, within a vocalization silent pauses could be no longer than $2.0 \mathrm{~s}$ ). We identified these types audio-visually, by listening to recordings and visually inspecting sonograms in Raven Pro 1.5 (Cornell Lab of Ornithology, Ithaca).

\section{Lyrebird-Specific Vocalizations (Alarm Calls and Song)}

Lyrebird-specific vocalizations have not been described in females; therefore, to identify lyrebird-specific alarm calls and whistle songs we referred to our recordings of male lyrebird vocalizations from earlier studies (Dalziell, 2012; Dalziell and Magrath, 2012; Dalziell et al., 2013), published sonograms of males (Powys, 1995; Robinson and Curtis, 1996; Higgins et al., 2001), and a single sonogram of a female vocalization (Higgins et al., 2001). Detailed written descriptions also informed our identification of lyrebird-specific alarm calls (reviewed in Higgins et al., 2001). This conservative approach increased our confidence 
that all sounds classified as lyrebird-specific were in fact correctly classified (thus minimizing type I errors).

\section{Mimetic Vocalizations}

To identify mimetic vocalizations, we compared recordings of lyrebirds to recordings of putative model species. Recordings of models were sourced from our own recordings, the Macaulay Library of Animal Sounds (Cornell Lab of Ornithology), the open source web-based archive 'Xeno-canto' (Xeno-canto Foundation), and commercial recordings (Plowright et al., 2007; McNabb, 2008; Morcombe and Stewart, 2014). Both authors were involved in the audiovisual identification of mimetic vocalizations.

Mimetic vocalizations were further subdivided by the criterion that all elements within a single vocalization were imitations of the same model species and were of the same element type (e.g., all elements within a single mimetic vocalization could be either imitations of alarm calls or song elements but they could not be both). These subdivisions were then allocated to one of three 'mimetic categories' based on the possible function of the heterospecific sounds for the mimicking lyrebird: (i) Predator imitations were imitations of the calls or songs of likely predators of adults and/or nests of lyrebirds, (ii) Alarm imitations were imitations of the alarm calls of birds likely to be harmless to lyrebirds, and (iii) Non-alarm imitations were imitations of the songs and other non-alarm vocalizations of birds harmless to lyrebirds. All mimetic categories were mutually exclusive.

\section{Unknown Vocalizations}

Of all vocalizations in our dataset $(n=1135), 9.9 \%$ were not classifiable as lyrebird-specific or as mimetic, and were classified instead as 'unknown.' Some of these unknown vocalizations may have been female lyrebird-specific vocalizations that were wholly unlike those of male lyrebirds so that no published examples were available, whereas others may have been imitations of models that we were unable to identify.

\section{Statistical Analysis}

To examine how the structure of vocalizations varied with context, GLMMs were constructed using GenStat 18 (VSN International, Hemel Hempstead, U.K.) and effects were estimated using restricted maximum likelihood (REML).

\section{Vocalization Types vs. Ecological Context}

To test how the different vocalization types varied with ecological context, we constructed a GLMM with a Poisson distribution and a log link function that included 'proportion of time vocalizing' (i.e., the total duration of each vocalization type per recording divided by the duration of the recording) as the dependent variable; 'vocalization type' (i.e., 'alarm call,' 'whistle song', 'mimetic vocalization,' 'unknown'), 'ecological context' ('foraging,' 'nest defense'), and their interaction term as fixed effects; and 'Female ID' as a random factor. A dispersion parameter was estimated to control for overdispersed residuals [dispersion parameter $\left(\operatorname{Sigma}^{2}\right)=0.020$, $\mathrm{SE}=0.0039]$. We evaluated the explanatory power of predictive factors using a backwards-stepwise selection procedure.

\section{Temporal Association between Mimetic and Lyrebird-Specific Vocalizations}

To examine the temporal association between mimetic and lyrebird-specific vocalizations, we compared the expected vs. observed probability distributions of vocalization types that immediately followed a mimetic vocalization.

To ensure that we only compared vocalizations that were closely associated in time, we included only vocalizations that followed within $8.4 \mathrm{~s}$ of a mimetic vocalization (corresponding to 75th percentile of the length of pauses between vocalizations within a recording). From these, we calculated the number of expected vocalizations of each vocalization type (i.e., 'alarm call,' 'whistle song,' 'mimetic vocalization,' 'unknown'), for each female, given the total number of mimetic vocalizations that she produced and the frequency of those types in the recordings. Thus, each female was given eight 'vocalization counts' consisting of four 'observed' and four 'expected' counts (one each for each vocalization type).

Next, we fitted a GLMM with a Poisson distribution and a log link function that included 'vocalization count' as the dependent variable; 'vocalization type,' 'observed vs. expected,' and their interaction term as fixed effects; and 'Female ID' as a random factor. A dispersion parameter was estimated to control for over-dispersed residuals [dispersion parameter $\left(\operatorname{Sigma}^{2}\right)=2.276$, $\mathrm{SE}=0.4070]$. Since the expected vocalization type frequencies were calculated from the data, we penalized the model with one additional residual degree of freedom.

Here, the key prediction is that if mimetic vocalizations are more closely associated with a particular vocalization type than expected by chance, then the interaction term should be significant.

\section{Mimetic Vocalization Categories vs. Context}

Finally, we examined whether females modified their 'mimetic categories' of mimetic vocalizations ('predator,' 'alarm,' 'nonalarm') according to the ecological context ('foraging' vs. 'nest defense') in which they were produced. To do this, we fitted a GLMM with a Poisson distribution and a log link function that included the number of mimetic vocalizations produced by females as the dependent variable; 'context,' 'mimetic category,' and their interaction term as fixed effects; and 'Female ID' as a random factor. A dispersion parameter was estimated to control for over-dispersed residuals [dispersion parameter $\left(\operatorname{Sigma}^{2}\right)=$ $1.572, \mathrm{SE}=0.3900$ ]. One individual female was excluded from the final model because she exerted a disproportionate influence on the model predictions; however, results were qualitatively the same and significant whether or not this female was included.

\section{RESULTS}

\section{Structure}

Female superb lyrebirds regularly produced complex and highly varied vocal sounds (Figure 1; Supplementary Audio S2) 
comprising both lyrical pure-tone sequences of song-like elements as well as explosive and arresting calls. Within these long and varied bouts, we identified three broad types of vocalizations: (i) characteristic alarm calls unique to lyrebirds (Figure 2), (ii) a lyrebird-specific multi-element song (Figure 3), and (iii) imitations of other species of bird (Figure 4) (henceforth: 'alarm calls,' 'whistle songs', and 'mimetic vocalizations' respectively: details below).

\section{Lyrebird-Specific Alarm Calls and Whistle Songs}

Lyrebird-specific alarm calls were highly distinctive in our recordings and were produced by most females (12/15). We classified three sounds as alarm calls (Table 1A; Figure 2): highpitched and often ear-splitting 'scream' calls ('intense alarm call', sonogram N, p. 162, Higgins et al., 2001); guttural alarm calls that were low-pitched and broadband; and a two-note alarm call (similar to the 'aw-kok' call: Smith, 1988). All three calls are associated with multiple lyrebird populations (AHD, personal observation) and are similar to previous written descriptions (reviewed in Higgins et al., 2001).

Unexpectedly, female lyrebirds also regularly produced a species-specific melodic vocalization (13/15 females: Figures 3A-C, Table 1A). These vocalizations were very similar in structure to the 'whistle songs' described for male lyrebirds (Zann and Dunstan, 2008; Dalziell, 2012; also called 'territorial song': Powys, 1995; Higgins et al., 2001) (Figure 3D). Thus, we name these female vocalizations 'whistle songs.'

\section{Mimetic Vocalizations}

Mimetic vocalizations were recorded in 11 of 15 nesting female lyrebirds (Table 1B). Across individuals, females most commonly imitated the vocalizations of other avian species, particularly those of two known predators of birds-the collared sparrowhawk (Accipiter cirrocephalus) and gray goshawk-as well as the calls of a large harmless cockatoo, the yellow-tailed black-cockatoo (Calyptorhynchus funereus), and a variety of vocalizations of a colonial honeyeater, the bell miner (Manorina melanophrys) (Figures 4A-E). Across females, we identified imitations of 19 species of bird (Table 1B) and all were found within our study site. There was considerable variation among female lyrebirds in the proportion of vocalizations that we could identify as mimetic. Some individuals did not appear to produce any mimetic sounds at all, but in one individual almost $75 \%$ of all vocalizations were imitations of other species.

Within female lyrebird vocalizations, we did not identify any imitations of sounds of human origin, despite the regular presence of people in the study site. Females could imitate nonvocal sounds, as we clearly identified imitations of bird wing beats, and one lyrebird appeared to imitate the distinctive squeak sound of two trees rubbing together in high winds, although in this case we were unable to obtain a recording of the suspected model sound.

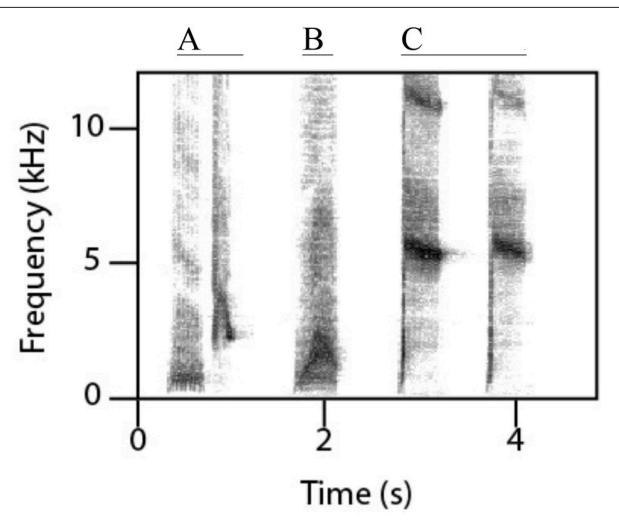

FIGURE 2 | Lyrebird-specific alarm calls. The three alarm calls most commonly produced by female lyrebirds are: (A) a two-note alarm call ('aw-kok'), (B) a guttural alarm call comprising one or more elements (one element shown here), and (C) a scream-like call ('intense alarm call') comprising one or more elements (two elements shown here) (See Table 1A for the distribution of lyrebird-specific alarm calls among females).

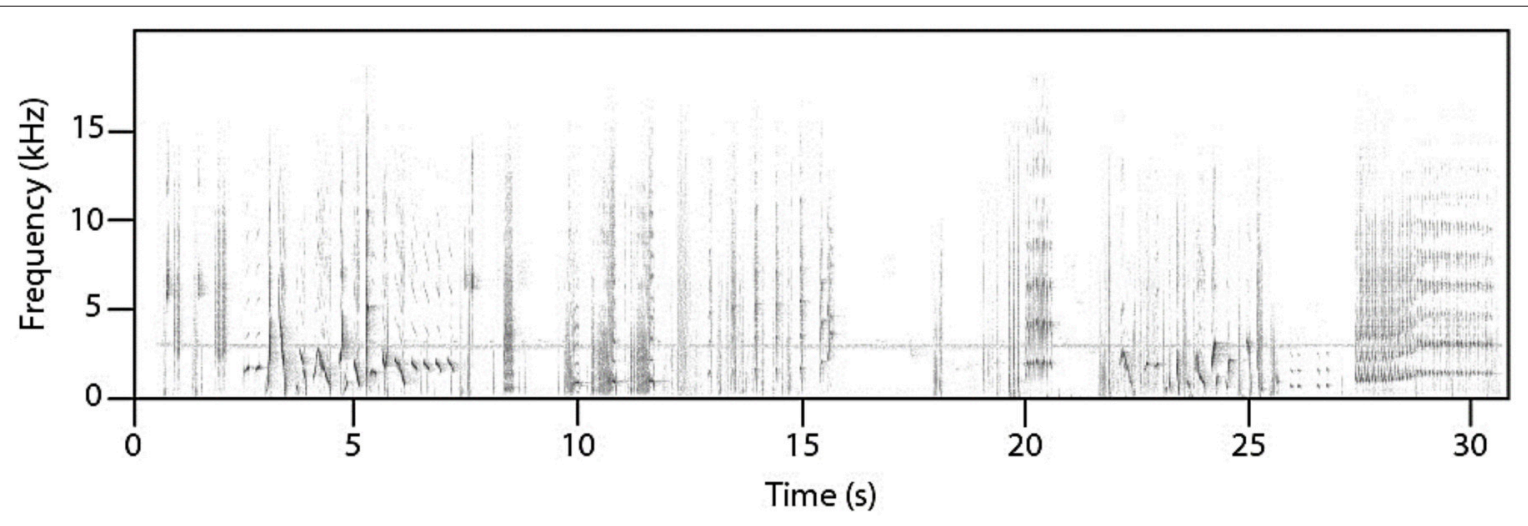

FIGURE 1 | A sample of an unedited recording of a female lyrebird vocalizing during nest defense. The apparent line at $3 \mathrm{kHz}$ is the incessant song of a white-throated treecreeper (Cormobates leucophaea), all other sounds are produced by the female lyrebird (See Supplementary Audio S2 for the audio file). 
TABLE 1 | (A) Lyrebird-specific vocalizations in recordings of 15 adult female superb lyrebirds, (B) Mimetic vocalizations in recordings of 11 adult female superb lyrebirds ( 3 females we recorded did not produce mimetic vocalizations).

\begin{tabular}{|c|c|c|c|c|}
\hline Vocalization type & \multicolumn{2}{|r|}{ Name } & \multicolumn{2}{|c|}{ Female ID* } \\
\hline \multicolumn{5}{|l|}{ A } \\
\hline Alarm & \multicolumn{2}{|r|}{ Scream } & \multicolumn{2}{|c|}{ A,B,C,D,F,G,H,I,J,N } \\
\hline Alarm & & Guttural alarm & \multicolumn{2}{|c|}{$\mathrm{A}, \mathrm{B}, \mathrm{D}, \mathrm{F}, \mathrm{K}, \mathrm{M}, \mathrm{N}, \mathrm{D}$} \\
\hline Alarm & & 'Aw-kok' & \multicolumn{2}{|c|}{$\mathrm{A}, \mathrm{F}, \mathrm{K}, \mathrm{M}, \mathrm{N}$} \\
\hline Song & & Whistle song & \multicolumn{2}{|c|}{$\mathrm{A}, \mathrm{B}, \mathrm{C}, \mathrm{D}, \mathrm{E}, \mathrm{G}, \mathrm{I}, \mathrm{J}, \mathrm{K}, \mathrm{L}, \mathrm{M}, \mathrm{N}, \mathrm{O}$} \\
\hline \multicolumn{5}{|l|}{$B^{\star \star}$} \\
\hline Accipiter cirrocephalus & Collared sparrowhawk & Territorial call & Predator & $\mathrm{A}, \mathrm{C}, \mathrm{F}, \mathrm{K}, \mathrm{M}, \mathrm{N}$ \\
\hline Calyptorhynchus funereus & Yellow-tailed black-cockatoo & Non-alarm call & Non-alarm & $\mathrm{A}, \mathrm{C}, \mathrm{F}, \mathrm{K}, \mathrm{L}, \mathrm{M}$ \\
\hline Accipiter novaehollandiae & Gray goshawk & Territorial call & Predator & $\mathrm{A}, \mathrm{F}, \mathrm{K}, \mathrm{M}, \mathrm{N}$ \\
\hline Strepera graculina & Pied currawong & Song & Predator & $E, M$ \\
\hline Manorina melanophrys & Bell miner & Song & Non-alarm & $\mathrm{D}$ \\
\hline Manorina melanophrys & Bell miner & Unknown & Non-alarm & $\mathrm{D}$ \\
\hline Platycercus elegans & Crimson rosella & Song & Non-alarm & $\mathrm{C}$ \\
\hline Platycercus elegans & Crimson rosella & Alarm & Alarm mimicry & $E$ \\
\hline Rhipidura albiscapa & Gray fantail & Mobbing call & Alarm mimicry & C \\
\hline Scythrops novaehollandiae & Channel-billed cuckoo & Non-alarm call & Non-alarm & C \\
\hline Myiagra rubecula & Leaden flycatcher & Unknown & Non-alarm & C \\
\hline Calyptorhynchus lathami & Glossy black-cockatoo & Non-alarm call & Non-alarm & C \\
\hline Alisterus scapularis & Australian king-parrot & Alarm call & Alarm mimicry & C \\
\hline Unknown & Wingbeats & NA & Not classified & C \\
\hline Eucalyptus spp. & Squeaky tree & NA & Not classified & C \\
\hline
\end{tabular}

*The females that produced each vocalization type are individually identified by a letter (See Figure $\mathbf{2}$ for sonograms of alarm vocalizations, and Figure $\mathbf{3}$ for sonograms of song). ${ }^{*} \boldsymbol{B}$ : For each mimetic vocalization, we identified the species and the type of vocalization that was imitated (e.g., song, alarm call etc.). These two properties were used to classify mimetic

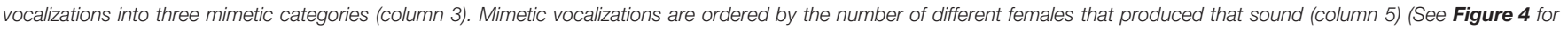
sonograms of a sample of mimetic vocalizations).

\section{Function and Context}

Female lyrebirds regularly vocalized while foraging away from their nests $(n=10)$ and during nest defense $(n=8)$, with a trend toward a higher vocalization rate during the latter $[2.3 \pm 2.11$ vs. $5.5 \pm 3.90 \mathrm{~s} / \mathrm{min}$, respectively; Welch's ANOVA (for uneven SD): $\left.F_{(1,10.4)}=4.33, P=0.063\right]$. However, female lyrebirds were completely silent when courting with males on display mounds $\left(n_{\text {interactions }}=27, n_{\text {males }}=15\right)$, ruling out any function for elaborate vocalizations by females during sexual interactions with males.

Female lyrebirds produced different types of vocalizations in different contexts (Figure 5, Table 2). Females sang whistle songs while foraging but rarely produced mimetic vocalizations or lyrebird-specific alarm calls. However, during nest defense females produced mostly lyrebird-specific alarm calls and mimetic vocalizations. Vocalizations that we could not classify were produced at similar rates to mimetic vocalizations across contexts, suggesting that such sounds were either imitations of sounds we were unfamiliar with, or poor imitations.

Mimetic vocalizations were non-randomly associated with vocalization types (Figure 6, Table 3). Mimetic vocalizations were more likely to be followed by mimetic vocalizations but were less likely to be followed by lyrebird-specific alarm vocalizations, compared to the expected frequencies of vocalization types. 


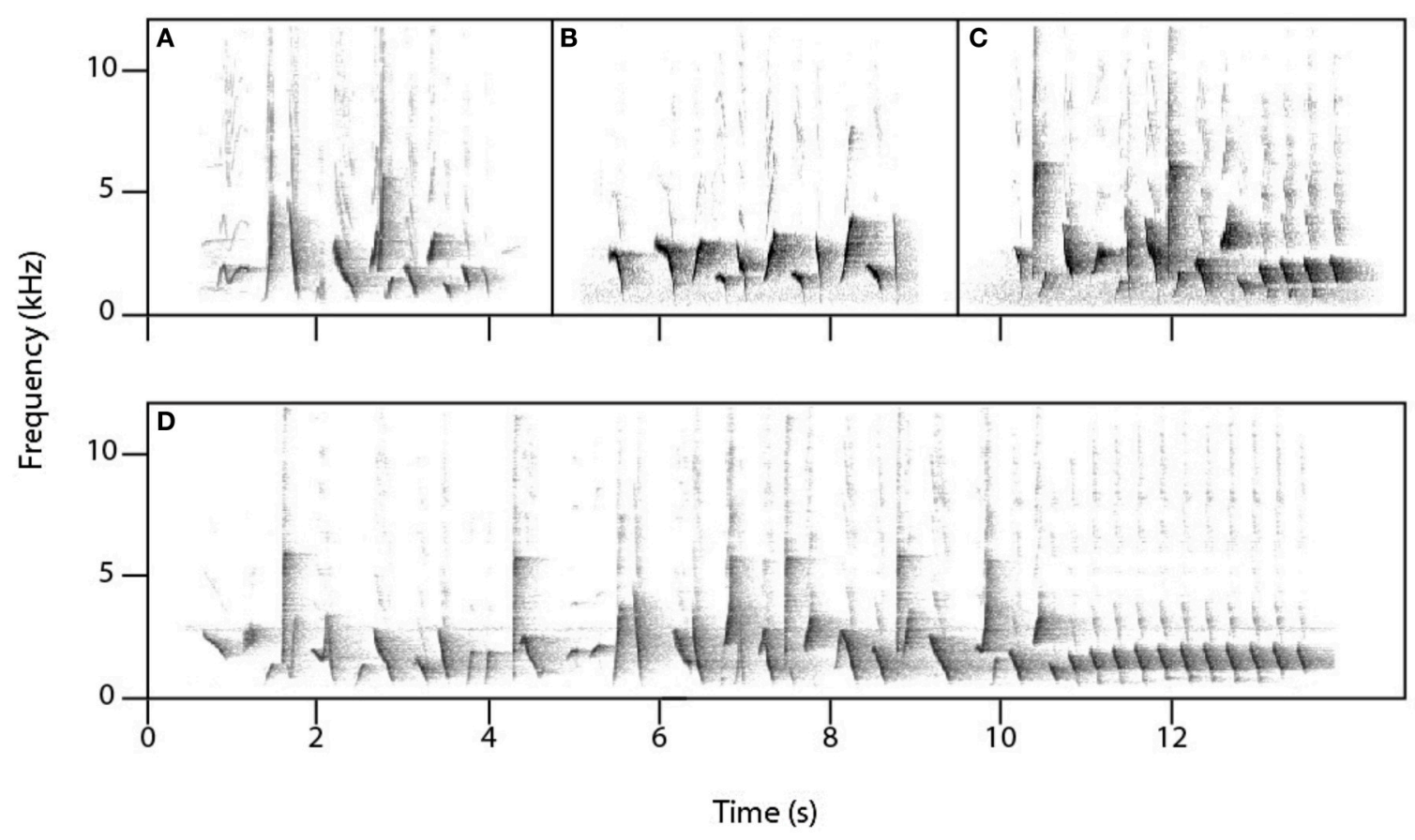

FIGURE 3 | Lyrebird-specific 'whistle song' as performed by three females (A-C) and a male (D).

TABLE 2 | Results from a generalized linear mixed model relating the proportion of time (of total recording time) females produced each of the four vocalization types (mimetic vocalizations, lyrebird-specific alarm, lyrebird-specific song and unknown), and ecological contexts (foraging forays vs. nest defense) (See also Figure 5).

\begin{tabular}{|c|c|c|c|c|c|c|c|}
\hline Effects & & Estimate & SE & Approx. F-statistic & Numerator d.f. & Denominator d.f. & $\boldsymbol{P}$ \\
\hline Random & Female & 0.369 & 0.266 & & & & \\
\hline \multirow[t]{3}{*}{ Fixed } & Constant & -5.13 & 0.602 & & & & \\
\hline & Context & & & 3.76 & 1 & 39.4 & 0.060 \\
\hline & Vocalization type ${ }^{\star}$ Context & & & 3.05 & 3 & 51.0 & 0.037 \\
\hline
\end{tabular}

Significant $P$-values $(<0.05)$ are highlighted in bold.

Finally, there was a difference in the composition of mimetic vocalization categories between contexts (Figure 7, Table 4). During nest defense females imitated all three mimetic vocalization types; however, during foraging they imitated the songs and calls of predators, while rarely imitating harmless model species.

\section{DISCUSSION}

Nesting female superb lyrebirds regularly produced complex vocalizations comprising a variety of species-specific sounds as well as accurate vocal imitations of other species. While preliminary, our results are consistent with a nest defense function for lyrebird-specific 'alarm' calls, and a territory defense function for the whistle song. Mimetic vocalizations likely play a role in both contexts but may have more than one function. These results contrast with prevailing notions that female lyrebird vocalizations are rare (Higgins et al., 2001) and of secondary importance (Robinson, 1975) to those of males. Instead, these results highlight the hidden complexity of female vocalizations in oscine passerines.

\section{Lyrebird-Specific Vocalizations}

Distinctive lyrebird-specific alarm calls formed a substantial part of the vocal repertoire of females, but were more strongly associated with nest defense than with foraging, consistent with a nest defense function. In lyrebirds, the burden of nestdefense is carried solely by the female. Offspring survival is an essential component of inclusive fitness and therefore nest defense strategies are likely to be under strong selection in birds with few, single-egg breeding attempts, like lyrebirds. 


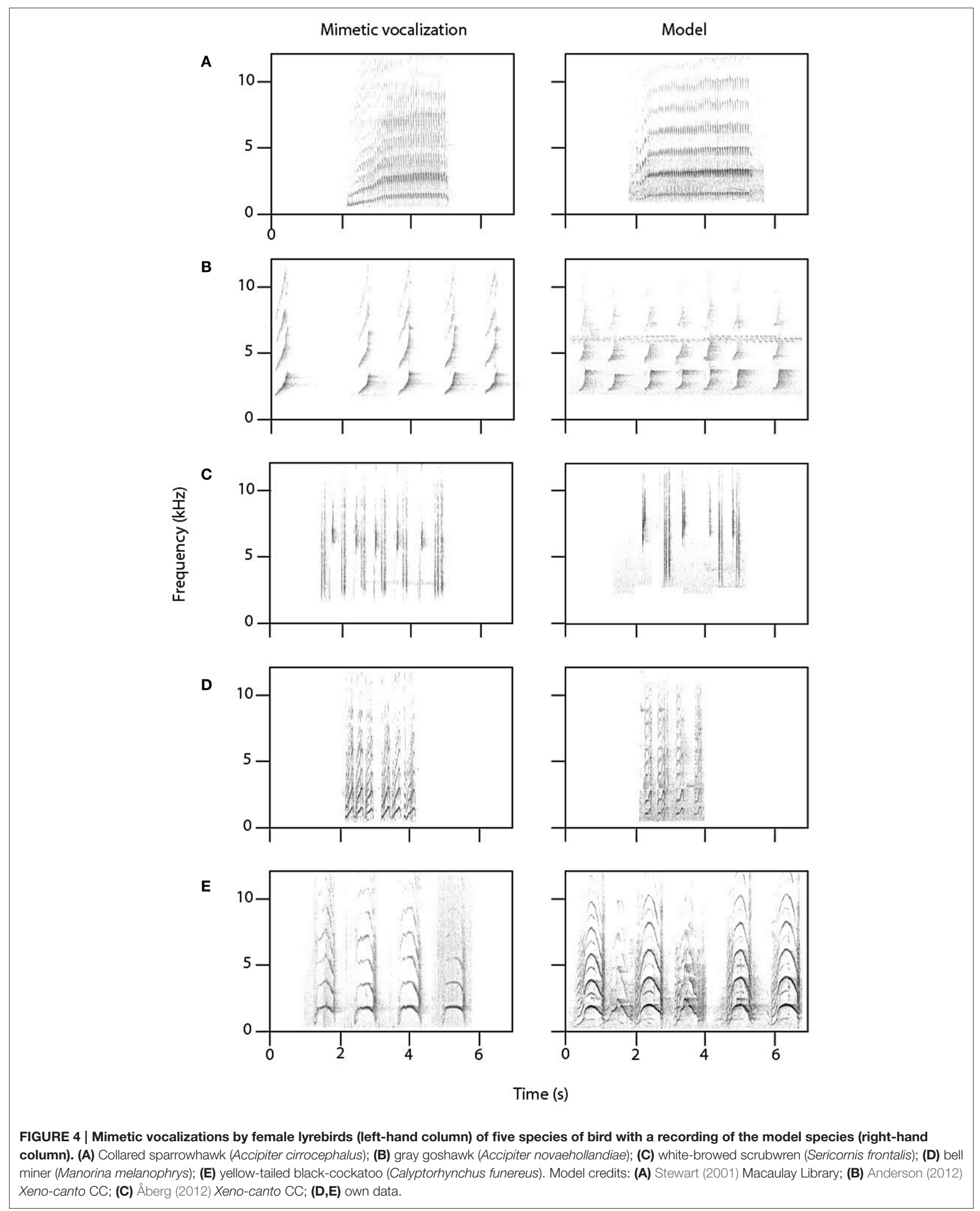


TABLE 3 | Results from a generalized linear mixed model comparing the observed frequency of different 'types' of vocalization (mimetic, lyrebird-specific alarm, whistle song, and unknown) that followed a mimetic vocalization, and the expected distribution of types calculated from the overall frequencies of each type within recordings (See also Figure 6).

\begin{tabular}{|c|c|c|c|c|c|c|c|}
\hline Effects & & Estimate & SE & Approx. F-statistic & Numerator d.f. & Denominator d.f. & $P$ \\
\hline \multirow[t]{3}{*}{ Fixed } & Constant & 1.03 & 0.432 & & & & \\
\hline & Expected vs. Observed & & & 0.01 & 1 & $61.5^{*}$ & $>0.9$ \\
\hline & Vocalization type* Expected vs. Observed & & & 5.20 & 3 & $61.5^{*}$ & $<0.01$ \\
\hline
\end{tabular}

Significant P-values (<0.05) are highlighted in bold.

"An additional residual degree of freedom is associated with the calculation of the 'Expected vs. Observed' factor.

TABLE 4 | Results from a generalized linear mixed model of the number of different mimetic vocalizations per minute by context (Foraging vs. nest defense) and the category of mimetic vocalization (predator, alarm, or non-alarm) (See also Figure 7).

\begin{tabular}{|c|c|c|c|c|c|c|c|}
\hline Effects & & Estimate & SE & Approximate F statistic & Numerator d.f. & Denominator d.f. & $\boldsymbol{P}$ \\
\hline Random & Female & 3.38 & 1.68 & & & & \\
\hline \multirow[t]{4}{*}{ Fixed } & Constant & -2.00 & 0.856 & & & & \\
\hline & Context & & & 0.94 & 1 & 43.5 & 0.337 \\
\hline & Mimicry type & & & 7.67 & 2 & 32.5 & 0.002 \\
\hline & Context*Mimicry category & & & 4.89 & 2 & 32.5 & 0.014 \\
\hline
\end{tabular}

Significant $P$-values $(<0.05)$ are highlighted in bold.

Accordingly, female lyrebirds vigorously defend their nests (Supplementary Video S1), closely approaching and sometimes physically attacking avian nest predators or humans near the nest (AHD and JAW unpublished data; Reilly, 1970; Lill, 1980). The conspicuousness and noxiousness of lyrebird alarm calls given during these events is often remarked upon (Higgins et al., 2001), and while it is likely that they play a role in nest defense, as they do in other bird species (Caro, 2005), it is as yet unclear how these calls reduce depredation.

Females regularly sang a loud, multi-element species-specific song analogous to the male 'whistle song' (Powys, 1995; Robinson and Curtis, 1996; Zann and Dunstan, 2008). Our results are consistent with a territory defense function for the whistle song, as females most often produced whistle songs while foraging away from the nest, and appeared to counter-sing to conspecifics-a common territorial defense behavior in other species (Catchpole and Slater, 2008). Studies of marked female lyrebirds show that they are territorial when breeding (e.g., Kenyon, 1972). Females can engage in female-female combat "just as aggressively as males" (p. 153, Higgins et al., 2001) and even destroy the nests of neighbors (Reilly, 1970). Given this backdrop of intra-sexual competition for nesting territories it is likely that the whistle song functions in the defense of breeding territories, as has been shown for females in other bird species (reviews: Langmore, 1998; Hall, 2004, 2009; also Brunton et al., 2008; Geberzahn et al., 2010; Krieg and Getty, 2016).

\section{Mimetic Vocalizations}

Female lyrebirds imitated a range of different sounds in their environment but most commonly those associated with alarm, such as the mobbing alarm calls of harmless species of bird and the calls of dangerous predators. Females imitated during

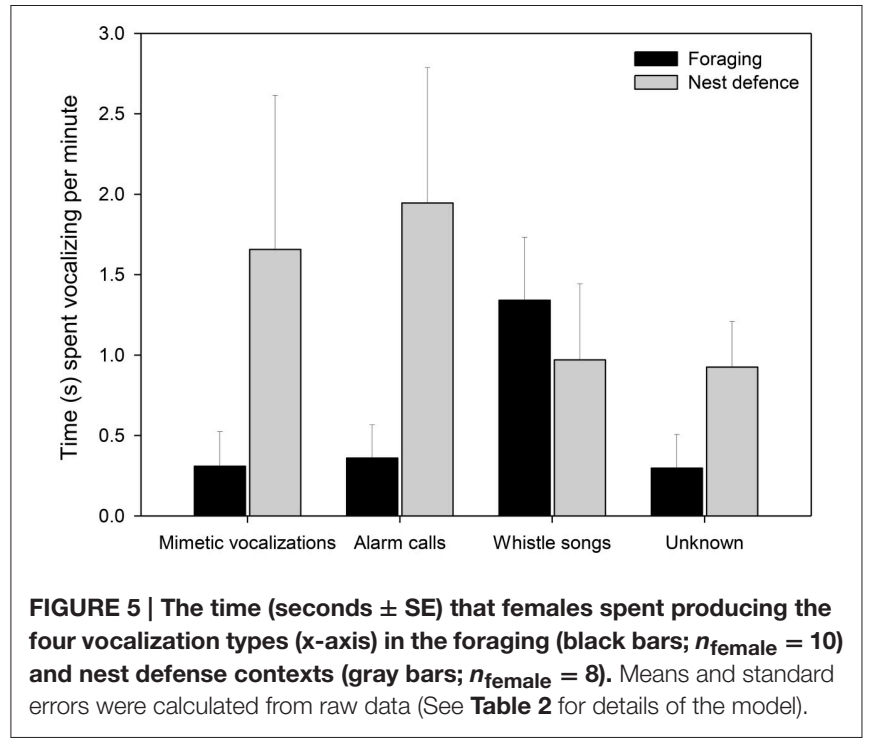

both nest defense and foraging but imitated more during nest defense, suggesting that mimetic vocalizations function in an antipredator context. Intriguingly however, there was a difference in the composition of the mimetic repertoires used in these contexts, with imitations of heterospecific alarm calls appearing more frequently during nest defense, whereas predator call imitations occurred similarly often in both the contexts. The predator calls that were imitated by most females were those of collared sparrowhawks and gray goshawks. These Accipiter spp. are known to attack adult female lyrebirds (Lill, 1980) and are therefore also likely predators of fledglings. It is tempting to speculate that by 

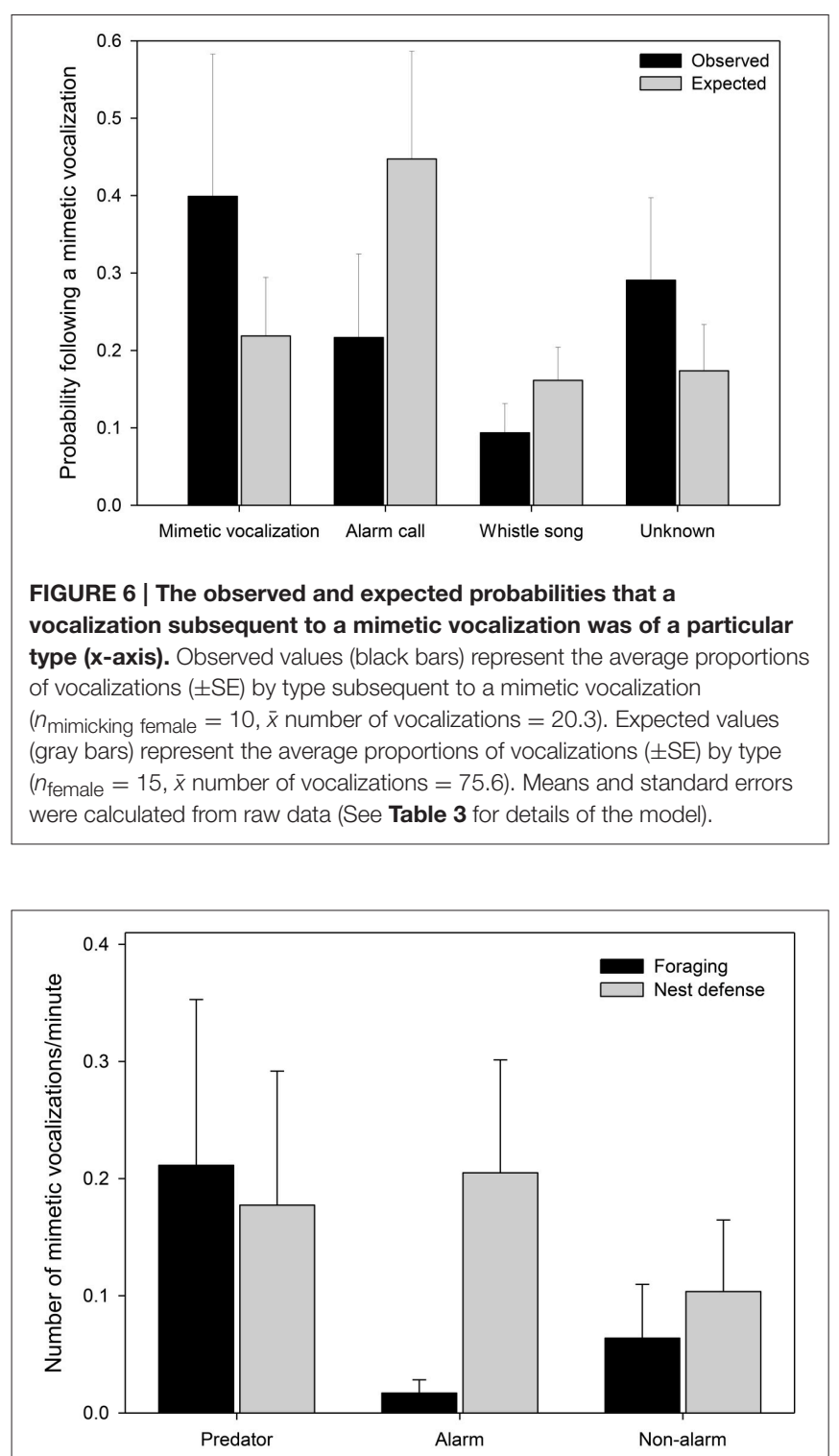

FIGURE 7 | The number of mimetic vocalizations observed per minute by category of mimetic vocalization (x-axis) during foraging forays (black bars) and nest defense (gray bars) ( $n_{\text {mimicking female }}=10$, $\overline{\boldsymbol{x}}$ number of vocalizations $\mathbf{= 2 0 . 3}$ ). Means and standard errors were calculated from raw data (See Table 4 for details of the model).

imitating Accipiter hawks, females create the acoustic illusion that dangerous raptors are present ('crying wolf'-see also Flower, 2011; Flower et al., 2014; Igic et al., 2015), thus decreasing the attractiveness of their territories (Rechten, 1978). This intriguing hypothesis could be investigated experimentally by examining responses of females to playback of imitated predator calls.

Given the likely roles of mimetic alarm vocalizations and lyrebird-specific alarm calls in nest defense, we expected that these mimetic and non-mimetic alarms would be positively associated, as has been found in other avian mimics (Goodale and Kotagama, 2006). Therefore, it was somewhat surprising that females were less likely to follow a mimetic vocalization with a lyrebird-specific alarm call than would be expected by chance. One explanation for this negative association is that they represent alternative nest-defense strategies. This could reflect age-dependent vocal learning constraints that are thought to affect mimetic ability in males (Zann and Dunstan, 2008). If the ontogeny of female mimetic vocalizations is similar to that of males, the option of producing effective mimetic vocalizations may be available only to older females, whereas alarm calls would be produced predominantly by younger females that are less vocally developed.

Do mimetic vocalizations of female lyrebirds constitute functional mimicry? Vocalizations resembling those of heterospecifics can result from several processes, including chance, common ancestry, ecological convergence, or as byproducts of vocal learning (reviewed in Dalziell et al., 2015). To be considered functional mimicry, however, the resemblance of a vocalization to a model should induce a behavioral change in receivers that provides a selective benefit the mimic (Dalziell et al., 2015). Clearly, in females not all mimetic vocalizations can be functional-it is difficult to imagine how receivers might respond to the sounds of a squeaking tree in a way that benefits a lyrebird! Nevertheless, the context-dependence of female mimetic vocalizations suggests that different types perform different functions, and so functional mimicry is plausible.

\section{Are Female Vocalizations By-Products of Selection for Vocal Complexity in Males?}

Overall, our findings are not consistent with the hypothesis that vocalizations by female lyrebirds are functionless byproducts of selection for vocal complexity in males. First, females varied their vocalizations predictably with female-only activities, as whistle songs were primarily associated with a femalefemale competition context, and mimetic vocalizations with nest defense. During courtship females were completely silent. Males, however, produce whistle song and mimetic vocalizations together and almost exclusively during sexual advertisement and courtship (Powys, 1995; Robinson and Curtis, 1996; Zann and Dunstan, 2008; Dalziell, 2012). This sex-specific contextdependence supports the notion that different vocalizations perform functions important for mediating fitness in both females and males. Second, females regularly imitated species that are only rarely imitated by males, such as Accipiter hawks and bell miners (Higgins et al., 2001; Zann and Dunstan, 2008; Dalziell, 2012); conversely, only one female imitated an Eastern whipbird, Psophodes olivaceus, which is a heterospecific that almost all males regularly imitate (AHD and JAW, pers. obs.; Zann and Dunstan, 2008). Thus, mimetic vocalizations appear to mediate different fitness benefits for males and females. For example, males may employ mimetic repertoires that best demonstrate their vocal agility and are thus most effective at attracting mates, while females selectively mimic sounds that best deter predators or conspecific competitors. These sex differences in mimetic repertoires also show that females and males acquire mimicry through different routes: 
females may directly copy model species or copy other females; whereas, males appear to learn their mimicry, at least in part, from other males (Robinson and Curtis, 1996; Higgins et al., 2001; Putland et al., 2006). In sum, both the functions and underlying mechanisms of elaborate vocalizations in lyrebirds appear to be different for both sexes, suggesting that males and females are under distinctly different selection pressures for vocal complexity.

\section{General Implications for Elaborate Vocalizations in Female Songbirds}

This study provides the first evidence of context-dependent female song in a species within the most basal clade of the oscine passerines. Identifying the ecological and life-history correlates of female song requires detailed study of song, particularly in species that diverged closest to the ancestral node (Odom et al., 2014). At present, little is known about female song in other early diverging species, with the exception of the Maluridae (Cooney and Cockburn, 1995; Hall and Peters, 2008; ColombelliNégrel et al., 2010; Dowling and Webster, 2013; Cain et al., 2015). Therefore, it is not yet clear what aspects of song in lyrebirds have been retained since their ancestor diverged from the main branch of the oscines, and what features have since evolved. Nonetheless, this study strengthens the conclusion of Odom et al. (2014) that female song has a deep evolutionary history.

Our results are only partially consistent with the ecological and life-history correlates of female song that have hitherto been identified (reviewed in Langmore, 1998; Hall, 2004; Slater and Mann, 2004; Odom et al., 2014). Like other species with female song, lyrebirds are non-migratory (Price, 2009; Logue and Hall, 2014), and do not experience the seasonal extremes associated with the absence of song in females of northern hemisphere species (Slater and Mann, 2004). Our findings support the idea that complex song by females is more commonly associated with intra-sexual competition for ecological resources than with mate attraction (Cooney and Cockburn, 1995; Hall and Peters, 2008; Illes and Yunes-Jimenez, 2009; Cain et al., 2015, see also Tobias et al., 2012), but contradict suggestions of an association with convergent sex roles (Slater and Mann, 2004). Indeed, our study suggests that elaborate female vocal displays can evolve even in species with strong selection for male extravagance. It also shows that the degree of sexual dimorphism in acoustic display does not have to reflect the extent of sexual dimorphism in plumage. This should not be unexpected, given recent studies showing that visual and acoustic display traits can evolve independently within males (Greig and Webster, 2013; Mason et al., 2014) and across the sexes (Soma and Garamszegi, 2015). Clearly, patterns of sexual dimorphism in acoustic display cannot always be inferred from sex differences in visual displays or other lifehistory traits.

There are two key implications of our study for the understanding of song learning in oscine passerines. First, by showing that females, like males, are capable of learning accurately a variety of sounds in their environment, our study suggests that sexual differences may lie more in what is learned rather than in the ability to learn per se (Riebel, 2003). Second, our study shows that complex learned vocalizations in females can specifically occur in a nest-defense context, in addition to the more traditionally recognized song contexts of competition for mates and resources (Langmore, 1998; Catchpole and Slater, 2008). Thus, vocal learning and song production are not fully equivalent. There is evidence that learned mimetic vocalizations are associated with nest defense in several oscine families (Dalziell et al., 2015) and can provide adaptive benefits (Igic et al., 2015), suggesting that nest-defense may constitute an important source of selection for complex learned vocalizations. A greater focus on female vocalizations may thus provide key insights into both the mechanisms and functions of learned vocalizations more broadly.

In conclusion, this study reveals elaborate female vocal displays in a basal oscine passerine widely depicted as a textbook example of sexual selection for male extravagance. It shows that female vocalizations can vary adaptively with female-only activities in a manner distinctly different from that of males. This adds to the growing evidence that not only do female oscine passerines regularly sing, but also that their vocalizations play an important role in mediating female fitness (Langmore, 1998; Hall, 2004, 2009; Odom et al., 2014; Hall and Langmore, $2016^{1}$ ). This evidence forces us to reconsider entrenched notions about the function, ontogeny, and evolutionary history of complex vocalizations-both mimetic and species-specific-and recognize the need for a more female-inclusive approach for a full understanding of the causes and consequences of avian vocal displays.

\section{ETHICS STATEMENT}

All work was approved by the Western Sydney University Animal Care and Ethics Committee (\#A10699) and the Cornell University Animal Care and Use Committee (2009-0105), and conducted under a Scientific Research Permit from the NSW National Parks and Wildlife Service, Office of Environment and Heritage (\#SL101351).

\section{AUTHOR CONTRIBUTIONS}

Both authors contributed to all aspects of this paper.

\section{ACKNOWLEDGMENTS}

We are grateful to Sarah Dzielski, Taylor Heaton Crisologo, James Purcell, Elizabeth Timmiss, Daniel Veronese, Samantha Yabsley, Asha Billing and Alex Maisey for help in the field as well as to Aaron Rice and Mike Webster for their helpful comments and discussions. We also thank NSW Parks and Wildlife service and Sydney Water for granting access to sites. Chris Banffy (NSW PW), Rosalie Chapple (Blue Mountains World Heritage Institute), Gavin Mckenzie (HIE), and Greg Budney (ML) provided valuable logistical assistance. The Hawkesbury

${ }^{1}$ http://journal.frontiersin.org/researchtopic/3139/female-song-fitness-costsand-benefits 
Institute for the Environment, the Macaulay Library and Mike Webster generously lent us equipment. We thank Michelle Hall, Naomi Langmore, and Katharina Riebel for suggesting this study and the two reviewers for helpful comments. This project was supported by a Cornell Lab of Ornithology Postdoctoral Fellowship to AHD, the HIE Outbound Research Exchange Program to JAW, the Ivy Expedition Fund of the Cornell Lab of Ornithology, the Cornell Open Access Publishing Program, and by the Hawkesbury Institute for the Environment.

\section{REFERENCES}

(2010). Lawrence's Thrush (Turdus lawrencii). Ithaca, NY: Cornell Lab of Ornithology. Available online at: http://neotropical.birds.cornell.edu/portal/ species/overview?p_p_spp $=551116$ (Accessed November 26, 2015).

Åberg, P. (2012). XC98523: White-Browed Scrubwren (Sericornis frontalis). Xenocanto Foundation. Available online at: http://www.xeno-canto.org/98523

Anderson, M. (2012). XC146127: Grey Goshawk (Accipiter novaehollandiae). Xenocanto Foundation. Available online at: http://www.xeno-canto.org/146127

Brunton, D., Evans, B., Cope, T., and Ji, W. (2008). A test of the dear enemy hypothesis in female New Zealand bellbirds (Anthornis melanura): female neighbors as threats. Behav. Ecol. 19, 791-798. doi: 10.1093/beheco/arn027

Cain, K. E., Cockburn, A., and Langmore, N. (2015). Female song rates in response to simulated intruder are positively related to reproductive success. Front. Ecol. Evol. 3:119. doi: 10.3389/fevo.2015.00119

Caro, T. (2005). Antipredator Defenses in Birds and Mammals. Chicago: University of Chicago Press.

Catchpole, C. K., and Slater, P. J. B. (2008). Bird Song: Biological Themes and Variations. Cambridge: Cambridge University Press.

Colombelli-Négrel, D., Robertson, J., and Kleindorfer, S. (2010). Risky revelations: superb fairy-wrens Malurus cyaneus respond more strongly to their mate's alarm song. J. Ornithol. 152, 127-135. doi: 10.1007/s10336-010-0557-1

Cook, L. C. (1915). Lyrebirds' habits. Emu 15, 52-52. doi: 10.1071/mu915051d

Cooney, R., and Cockburn, A. (1995). Territorial defense is the major function of female song in the superb fairy-wren, Malurus cyaneus. Anim. Behav. 49, 1635-1647. doi: 10.1016/0003-3472(95)90086-1

Dalziell, A. H. (2012). The Ecology of Vocal Mimicry in the Superb Lyrebird, Menura novaehollandiae. Doctor of Philosophy Ph.D. thesis, Australian National University.

Dalziell, A. H., and Magrath, R. D. (2012). Fooling the experts: accurate vocal mimicry in the song of the superb lyrebird, Menura novaehollandiae. Anim. Behav. 83, 1401-1410. doi: 10.1016/j.anbehav.2012.03.009

Dalziell, A. H., Peters, R. A., Cockburn, A., Dorland, A. D., Maisey, A. C., and Magrath, R. D. (2013). Dance choreography is coordinated with song repertoire in a complex avian display. Curr. Biol. 23, 1132-1135. doi: 10.1016/j.cub.2013.05.018

Dalziell, A. H., Welbergen, J. A., Igic, B., and Magrath, R. D. (2015). Avian vocal mimicry: a unified conceptual framework. Biol. Rev. 90, 643-668. doi: 10.1111/brv.12129

Delius, J. D. (1967). Displacement activities and arousal. Nature 214, 1259-1260. doi: $10.1038 / 2141259 \mathrm{a} 0$

Dowling, J. L., and Webster, M. S. (2013). The form and function of duets and choruses in red-backed fairy-wrens. Emu 113, 282-293. doi: 10.1071/MU12082

Dowsett-Lemaire, F. (1979). Imitative range of the song of the marsh warbler Acrocephalus palustris, with special reference to imitations of African birds. Ibis 121, 453-468. doi: 10.1111/j.1474-919X.1979.tb06685.x

Eens, M. (1997). Understanding the complex song of the European starling: an integrated ethological approach. Adv. Study Behav. 26, 355-434. doi: 10.1016/S0065-3454(08)60384-8

Flower, T. (2011). Fork-tailed drongos use deceptive mimicked alarm calls to steal food. Proc. R. Soc. Lond. Series B Biol. Sci. 278, 1548-1555. doi: 10.1098/rspb.2010.1932

\section{SUPPLEMENTARY MATERIAL}

The Supplementary Material for this article can be found online at: http://journal.frontiersin.org/article/10.3389/fevo. 2016.00034

\section{Supplementary Video S1 | Video of nest defense following a natural disturbance.}

Supplementary Audio S2 | Unedited 30-s sound recording of a female lyrebird vocalizing during nest defense (supplementary to Figure 1).

Flower, T. P., Gribble, M., and Ridley, A. R. (2014). Deception by flexible alarm mimicry in an African bird. Science 344, 513-516. doi: 10.1126/science.1249723

Frid, A., and Dill, L. M. (2002). Human-caused disturbance stimuli as a form of predation risk. Conserv. Ecol. 6:11. Available online at: http://www.consecol. org/vol6/iss1/art11/

Gammon, D. E., and Altizer, C. E. (2011). Northern mockingbirds produce syntactical patterns of vocal mimicry that reflect taxonomy of imitated species. J. Field Ornithol. 82, 158-164. doi: 10.1111/j.1557-9263.2011.00318.x

Geberzahn, N., Goymann, W., and ten Cate, C. (2010). Threat signaling in female song-evidence from playbacks in a sex-role reversed bird species. Behav. Ecol. 21, 1147-1155. doi: 10.1093/beheco/arq122

Goodale, E., and Kotagama, S. W. (2006). Context-dependent vocal mimicry in a passerine bird. Proc. R. Soc. Lond. Series B Biol. Sci. 273, 875-880. doi: 10.1098/rspb.2005.3392

Greig, E. I., and Webster, M. S. (2013). Spatial decoupling of song and plumage generates novel phenotypes between 2 avian subspecies. Behav. Ecol. 24, 1004-1013. doi: 10.1093/beheco/art005

Hall, M. L. (2004). A review of hypotheses for the functions of avian duetting. Behav. Ecol. Sociobiol. 55, 415-430. doi: 10.1007/s00265-003-0741-x

Hall, M. L. (2009). A review of vocal duetting in birds. Adv. Study Behav. 40, 67-121. doi: 10.1016/S0065-3454(09)40003-2

Hall, M. L., and Peters, A. (2008). Coordination between the sexes for territorial defence in a duetting fairy-wren. Anim. Behav. 76, 65-73. doi: 10.1016/j.anbehav.2008.01.010

Harcus, J. L. (1977). Functions of mimicry in vocal behavior of the chorister robin. Zeitschrift Tierpsychol. 44, 178-193. doi: 10.1111/j.1439-0310.1977.tb00992.x

Higgins, P. J., Peter, J. M., and Steele, W. K. (2001). Tyrant-Flycatchers to Chats. Handbook of Australian, New Zealand \& Antarctic Birds. Vol. 5. Melbourne: Oxford University Press.

I. W. (1944, July 1). Introducing Mrs Lyrebird, just another wife without help. The Argus Weekend Magazine 3.

Igic, B., McLachlan, J., Lehtinen, I., and Magrath, R. D. (2015). Crying wolf to a predator: deceptive vocal mimicry by a bird protecting young. Proc. R. Soc. Lond. B Biol. Sci. 282:20150798. doi: 10.1098/rspb.2015.0798

Illes, A. E., and Yunes-Jimenez, L. (2009). A female songbird out-sings male conspecifics during simulated territorial intrusions. Proc. R. Soc. Lond. B Biol. Sci. 276, 981-986. doi: 10.1098/rspb.2008.1445

Kenyon, R. F. (1972). Polygyny among superb lyrebirds in Sherbrooke forest park, Kallista, Victoria. Emu 72, 70-76. doi: 10.1071/MU972070

Kitson, A. E. (1905). Notes on the Victoria lyre-bird (Menura victoriae). Emu 5, 57-67. doi: 10.1071/MU905057

Krieg, C. A., and Getty, T. (2016). Not just for males: females use song against male and female rivals in a temperate zone songbird. Anim. Behav. 113, 39-47. doi: 10.1016/j.anbehav.2015.12.019

Langmore, N. E. (1998). Functions of duet and solo songs of female birds. Trends Ecol. Evol.13, 136-140. doi: 10.1016/S0169-5347(97)01241-X

Lill, A. (1979a). Assessment of male parental investment and pair bonding in the polygamous superb lyrebird. Auk 96, 489-498.

Lill, A. (1979b). Nest inattentiveness and its influence on development of the young in the superb lyrebird. Condor 81, 225-231. doi: 10.2307/1367621

Lill, A. (1980). Reproductive success and nest predation in the superb lyrebird, Menura superba. Aust. Wildl. Res. 7, 271-280. doi: 10.1071/WR9800271 
Lill, A. (2004). "Lyrebirds (Menuridae)," in Handbook of the Birds of the World Alive, eds J. del Hoyo, A. Elliott, J. Sargatal, D. A. Christie, and E. de Juana (Barcelona: Lynx Edicions). Available online at: http://www.hbw.com/node/ 57584

Logue, D. M., and Hall, M. L. (2014). Migration and the evolution of duetting in songbirds. Proc. R. Soc. B Biol. Sci. 281, 1-5. doi: 10.1098/rspb.2014.0103

Mason, N. A., Shultz, A. J., and Burns, K. J. (2014). Elaborate visual and acoustic signals evolve independently in a large, phenotypically diverse radiation of songbirds. Proc. R. Soc. B Biol. Sci. 281:20140967. doi: 10.1098/rspb.2014.0967

McNabb, E. (2008). Nightlife of Australia South-eastern Forests. Gembrook: [CD] Ninox Pursuits.

Morcombe, M., and Stewart, D. (2014). eGuide to The Birds of Australia. Available online at: http://www.mydigitalearth.com (Accessed November 26, 2015).

Odom, K. J., Hall, M. L., Riebel, K., Omland, K. E., and Langmore, N. E. (2014). Female song is widespread and ancestral in songbirds. Nat. Commun. 5, 1-6. doi: $10.1038 /$ ncomms 4379

Plowright, H., Buckingham, R., and Jackson, L. (2007). A Field Guide to Australian Birdsong [10 CDs]. Nunawading: Bird Observers Club of Australia.

Powys, V. (1995). Regional variation in the territorial songs of superb lyrebirds in the central tablelands of New South Wales. Emu 95, 280-289. doi: 10.1071/MU9950280

Price, J. J. (2009). Evolution and life-history correlates of female song in the New World blackbirds. Behav. Ecol. 20, 967-977. doi: 10.1093/beheco/arp085

Putland, D. A., Nicholls, J. A., Noad, M. J., and Goldizen, A. W. (2006). Imitating the neighbours: vocal dialect matching in a mimic-model system. Biol. Lett. 2, 367-370. doi: 10.1098/rsbl.2006.0502

Rechten, C. (1978). Interspecific mimicry in birdsong: does the Beau Geste hypothesis apply? Anim. Behav. 26, 305-306. doi: 10.1016/0003-3472(78)90034-9

Reilly, P. N. (1970). Nesting of the superb lyrebird in Sherbrooke Forest, Victoria. Ети 70, 73-78. doi: 10.1071/MU970073

Riebel, K. (2003). The "mute" sex revisited: vocal production and perception learning in female songbirds. Adv. Study Behav. 33, 49-86. doi: 10.1016/S00653454(03)33002-5

Riebel, K., Hall, M. L., and Langmore, N. E. (2005). Female songbirds still struggling to be heard. Trends Ecol. Evol. 20, 419-420. doi: 10.1016/j.tree.2005.04.024

Robinson, F. N. (1975). Vocal mimicry and the evolution of bird song. Emu 75, 23-27. doi: 10.1071/MU9750023
Robinson, F. N., and Curtis, H. S. (1996). The vocal displays of the lyrebirds (Menuridae). Emu 96, 258-275. doi: 10.1071/MU9960258

Robinson, F. N., and Frith, H. J. (1981). The superb lyrebird Menura novaehollandiae at Tidbinbilla, ACT. Emu 81, 145-157. doi: 10.1071/MU9810145

Slater, P. J. B., and Mann, N. I. (2004). Why do the females of many bird species sing in the tropics? J. Avian Biol. 35, 289-294. doi: 10.1111/j.0908-8857.2004.03392.x

Smith, L. H. (1988). The Life of the Lyrebird. Melbourne, VIC: William Heinemann Australia.

Smith, L. H. (1999). Structural changes in the main rectrices of the superb lyrebird Menura novaehollandiae in the development of the filamentary feathers. Emu 99, 46-59. doi: 10.1071/MU99007

Smith, L. H. (2004). Structural changes in the lyrate feathers in the development of the tail plumage of the superb lyrebird, Menura novaehollandiae. Emu 104, 59-73. doi: 10.1071/MU01020

Soma, M., and Garamszegi, L. Z. (2015). Evolution of courtship display in Estrildid finches: dance in relation to female song and plumage ornamentation. Front. Ecol. Evol. 3:4. doi: 10.3389/fevo.2015.00004

Stewart, D. (2001). 156568: Collared Sparrowhawk (Accipiter cirrocephalus). Cornell Lab of Ornithology Macaulay Library. Available online at: http://www.macaulaylibrary.org

Tobias, J. A., Montgomerie, R., and Lyon, B. E. (2012). The evolution of female ornaments and weaponry: social selection, sexual selection and ecological competition. Philos. Trans. R. Soc. B Biol. Sci. 367, 2274-2293. doi: 10.1098/rstb.2011.0280

Zann, R., and Dunstan, E. (2008). Mimetic song in superb lyrebirds: species mimicked and mimetic accuracy in different populations and age classes. Anim. Behav. 76, 1043-1054. doi: 10.1016/j.anbehav.2008.05.021

Conflict of Interest Statement: The authors declare that the research was conducted in the absence of any commercial or financial relationships that could be construed as a potential conflict of interest.

Copyright $\odot 2016$ Dalziell and Welbergen. This is an open-access article distributed under the terms of the Creative Commons Attribution License (CC BY). The use, distribution or reproduction in other forums is permitted, provided the original author(s) or licensor are credited and that the original publication in this journal is cited, in accordance with accepted academic practice. No use, distribution or reproduction is permitted which does not comply with these terms. 